\title{
Liquid chromatographic determination of citrinin residues in various meat products: A pioneer survey in Turkey
}

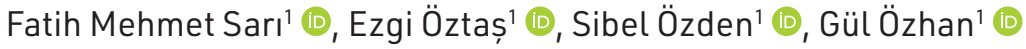 \\ ${ }^{1}$ Istanbul University, Faculty of Pharmacy, Department of Pharmaceutical Toxicology, Istanbul, Turkey
}

ORCID IDs of the authors: F.M.S. 0000-0002-8552-4676; E.0̈. 0000-0002-0718-2359; S.0̈. 0000-0002-1662-2504;

G.0̈. 0000-0002-6926-5723

Cite this article as: Sari, F. M., Oztas, S., Ozden, S., \& Ozhan G. (2020). Liquid chromatographic determination of citrinin residues in various meat products: A pioneer survey in Turkey. (Fabaceae). Istanbul Journal of Pharmacy, 50 (3), 195-201.

\begin{abstract}
Background and Aims: Occurence of the mycotoxin citrinin could increase during Monascus purpureus fermentation in red yeast rice resulting in contamination of meat products when the red yeast rice is used as food additive. The aim of this study was to investigate extraction of citrinin from meat products by different extraction methods including LLE, QuEChERS and IAC methods.

Methods: Because of high sensitivity IAC method was selected for the extraction of citrinin in 33 meat products (salami, sausage and minced meat), then citrinin was analysed by HPLC- FLD.

Results: IAC method was linear in the range of $0.25-100 \mathrm{ng} / \mathrm{g}\left(r^{2} \geq 0.999\right)$ in meat products. Citrinin was found at 0.28 to 1.79 $\mathrm{ng} / \mathrm{g}$ in 6 of the 19 samples $(36.84 \%)$; and in one sausage sample contained citrinin at LOD level. However, citrinin was not detected in the salami and minced meat samples.

Conclusion: Our results indicated that citrinin in meat products could be an important health concern. Since no limits were set in food products, regulations should be developed concerning the presence of citrinin in other products as well as meat products, in Turkey.
\end{abstract}

Keywords: Citrinin, HPLC-FLD, Meat products

\section{INTRODUCTION}

Mycotoxins are secondary metabolites produced by fungi due to inappropriate temperature and humidity conditions during poor cultivation and storage conditions. Until now, about 400 mycotoxins, mainly produced by Aspergillus, Penicillium, Fusarium, Alternaria, Cladosporium and Rhizopus species, have been identified (Pohland, 1993; Moss, 2002; Pal, Gizaw, Abera, Shukla, \& Hazarika, 2015). Since mycotoxins cause serious harmful effects on human health and the environment, the detection of mycotoxin residues has emerged in various raw and processed food products. Even if the studies have especially focused on aflatoxins, the interest in mycotoxins including ochratoxin A, patulin, citrinin and zearalenone has increased considerably. Also, mycotoxins can cause industrial and financial losses due to color change and unwanted odor in food products (Rawat, 2015). To minimize mycotoxin-mediated diseases, it is necessary to set the maximum values and the regulations on the mycotoxin content of food products. 
Citrinin, a pyran derivative, is predominantly produced by Penicillium, Aspergillus and Monascus species, and most commonly found in corn, rice, wheat, rye, barley, peanut, bread, fruits, oilseeds (Shu \& Lin, 2002; Chia-Hao, Feng-Yili, Li-Ting, Yi-Shen, \& Biing-Hui, 2009). Because of the positive effects of the traditional Chinese food, red yeast rice on the digestive system and blood circulation, it is considered a valuable dietary supplement worldwide (Li, Xu, Li, Chen, \& Ji, 2012; Srianta et al., 2014; Woo et al., 2014). Additionally, red yeast rice is widely used as a preservative, flavoring and food colorant, especially, in meat, fish and soybean products (Ma et al., 2000). Occurrence of citrinin could increase during Monascus purpureus fermentation in red yeast rice. Therefore, food processing for increasing the yield and attractiveness of the product is an important source of citrinin exposure as well as natural occurrence during agriculture.

The major adverse effects of citrinin on human health are nephrotoxicity and neurotoxicity, which can result in life-threatening consequences (Xu, Jia, Gu, \& Sung, 2006). Moreover, citrinin usually occurs simultaneously with ochratoxin $A$, which have both hepatotoxic, immunotoxic, embryotoxic/teratogenic and carcinogenic effects, synergistically (Speijers \& Speijers, 2014; Gupta, Srivastava, \& Lall, 2018). Citrinin caused lipid peroxidation, mitochondrial respiratory dysfunction, and inhibition of several antioxidant enzymes, and induced micronuclei formation, aneuploidy, and chromosomal abnormalities; while it did not lead to DNA strand breaks, it did lead to oxidative DNA damage and sister chromatid exchange (EFSA, 2012).

It is well established that mycotoxin-contaminated food/feed could have substantial impacts on the economy, human health and environment. It has to be mentioned that the contamination of several foods with citrinin has been observed all over the world. Citrinin has been detected in many stored and dry foods such as cereal (Molinié, Faucet, Castegnaro, \& Pfohl-Leszkowicz, 2005; Polisenska et al., 2010; EFSA, 2012), cereal-based foods (Vrabcheva, Usleber, Dietrich, \& Märtlbauer, 2000; Duarte, Pena, \& Lino, 2010; Zaied, Zouaoui, Bacha, \& Abid, 2012; EFSA, 2012), fruit juices, medical plants, nuts (EFSA, 2012), olives and olive oil (El Adlouni, Tozlovanu, Naman, Faid, \& Pfohl-Leszkowicz, 2006; Tokusoglu \& Bozoglu, 2010; EFSA, 2012), tomatoes (Tölgyesi, Stroka, Tamosiunas, \& Zwickel, 2015); cheese (Franco et al., 1996; EFSA, 2012), corn (Jackson, \& Ciegler, 1978; Janardhana, Raveesha, \& Shetty, 1999; Warth et al., 2012), beans (PetkovaBocharova Castegnaro, Michelon, \& Maru, 1991; EFSA, 2012), flour (Nishijima, 1984; Dick, Baumann, \& Zimmerli, 1988), several spices (Saxena \& Mehrotra, 1989; El-Kady, El-Maraghy, \& Mostafa, 1995), soy (Kononenko \& Burkin, 2008), rice (Hackbart, Prietto, Primel, Garda-Buffon, \& Badiale-Furlong, 2012; Nguyen, Tozlovanu, Tran, \& Pfohl-Leszkowicz, 2007), red mold rice (Li, Xu, Li, Chen, \& Ji, 2005; Li, Zhou, Yang, \& Ou-Yang, 2012; Childress, Gay, Zargar, \& Ito, 2013; Ostry, Malir, \& Ruprich, 2013; Liao, Chen, Lin, Chiueh, \& Shih, 2014; Ji et al., 2015), fermented meat products (Markov et al., 2013) and feed (Talmaciu Sandu, \& Banu, 2008).

There is a regulation for citrinin regarding the maximum levels in food supplements based on Monascus purpureus fermented rice within the European Commission Regulation (EC) 212/2014 (EU, 212/2014); however, there is no regulation in Turkey. Hence, there seems to be an urgent need to detect citrinin residues and set maximum limits. EC regulation has set the limit of $2 \mathrm{ng} / \mathrm{g}$ for citrinin in only red yeast rice (EU, 212/2014). Therefore, we aimed to detect citrinin residues in various meat products. For this purpose, three different extraction methods were used; LLE (LiquidLiquid Extraction), QuEChERS (Quick, Easy, Cheap, Effective, Robust and Safe) multi-residue and IAC (Immuno-Affinity Column) for the extraction of citrinin in salami, sausage, and minced meat samples. Because of its high sensitivity, the IAC method was selected for the extraction of citrinin in meat products. Then, the samples were analysed by high-performance liquid chromatography (HPLC)-fluorescence detection (FLD). The study will contribute to further investigations regarding the residue levels for citrinin in food products and the results could be considered by the regulatory affairs for the risk assessment process for citrinin.

\section{MATERIALS AND METHODS}

\section{Chemicals}

Citrinin was obtained from Sigma-Aldrich (Bellefonte, PA, USA, Cat. No: (1017) at the purity of $\geq 98 \%$. A standard stock solution was prepared at a concentration of $50 \mu \mathrm{g} / \mathrm{mL}$ in methanol, and kept at $4{ }^{\circ} \mathrm{C}$. Then, the HPLC standard solutions were prepared by serial dilutions at the concentration range of 0.25 $100 \mathrm{ng} / \mathrm{mL}$ in the mobile phase. The mobile phase was freshly prepared by mixing water:acetonitrile: 2-propanol (65:30:5, $\mathrm{v}: \mathrm{v}: \mathrm{v})$, and $\mathrm{pH}$ was adjusted to 2.95 with ortho-phosphoric acid. HPLC-grade methanol, acetonitrile, and other analytical grade reagents were purchased from Riedel-de Haën (Seelze, Germany) and Merck (Darmstadt, Germany).

\section{Samples}

A total of 33 meat products, including 19 branded sausages, 7 branded salami and 5 branded minced meat samples and 2 unlicensed open ground meat samples made from beef, lamb and turkey, was purchased from various supermarkets, delicatessens and butchers in Istanbul, Turkey during 2016-2018. Samples were collected as a minimum $1 \mathrm{~kg}$ in weight and immediately brought to the laboratory. After homogenization with IKA Ultra-Turrax disperser homogenizer (Bender\&Hobein GMBH, Maaßstr, Germany) at high speed, $10 \mathrm{~g}$ of each sample was aliquoted and stored in a polyethylene bag and kept at $-20^{\circ} \mathrm{C}$ until the day of analysis was conducted.

\section{Extraction of Citrinin LLE (Liquid-liquid extraction)}

Briefly, $1 \mathrm{~g}$ of the sample was extracted with $5 \mathrm{~mL}$ methanol:water (80:20, v:v) using the disperser homogenizer for 5 min. After centrifuging at 4000 rpm for 15 min, the sample extract was filtered through $0.45 \mu \mathrm{m}$ nylon syringe filter. Then, $100 \mu \mathrm{L}$ of the aliquot was injected into high-performance liquid chromatography HPLC-FLD.

2.3.2. QuEChERS (Quick, Easy, Cheap, Effective, Robust and Safe) multi-residue

The QuEChERS multi-residue kit was obtained from Restek Corp. (Bellefonte, PA, USA, Cat. No: 26221), and the extraction was done by manufacturer's instructions. Briefly, $1 \mathrm{~g}$ of the sample was extracted with $10 \mathrm{~mL}$ methanol with $0.1 \%$ acetic 
acid:water (80:20, v:v) using the disperser homogenizer for 1 min. The homogenized sample was added into the magnesium sulfate:sodium acetate (4:1) cleaning solution, shaken for $1 \mathrm{~min}$, then centrifuged at 4000 rpm for $5 \mathrm{~min}$. The supernatant was added into the magnesium sulfate:primary secondary amine $(3: 1, v: v)$ mixture, and shaken for 5 min, then centrifuged at $4000 \mathrm{rpm}$ for $5 \mathrm{~min}$. $10 \mathrm{~mL}$ of the supernatant was filtered through a $0.45 \mu \mathrm{m}$ nylon syringe filter, and $40 \mu \mathrm{L}$ of the aliquot was injected into HPLC-FLD.

\section{IAC (Immuno-affinity column)}

CitriTest $^{\mathrm{TM}}$ immunoaffinity columns were purchased from VICAM (Watertown, MA, USA), and the extraction was done according to manufacturer's instructions. Briefly, $1 \mathrm{~g}$ of the sample was extracted with $20 \mathrm{~mL}$ of methanol:water (70:30, v:v) on a shaker at $65^{\circ} \mathrm{C}$ for $15 \mathrm{~min}$. The supernatant was filtered through a black ribbon filter paper (Whatman, Sigma-Aldrich, Munich, Germany); and then, $1 \mathrm{~mL}$ of the filtrate was filtered through a $0.45 \mu \mathrm{m}$ nylon syringe filter. The second filtrate was completed into the final volume of $40 \mathrm{~mL}$ with phosphate buffer, and mixed well. Ten $\mathrm{mL}$ of filtrate (=0.04 g sample equivalent) was passed through a CitriTest $^{\text {TM }}$ immunoaffinity column attached to a vacuum manifold (VacElut 20 Manifold, Agilent Biotechnologies, Santa Clara, CA, USA) at a flow rate of 1 drop/second until air came through the column. The column was washed with $10 \mathrm{~mL}$ of $0.1 \%$ tween 20 / phosphate-buffered saline and $10 \mathrm{~mL}$ of water, then dried under a vacuum. Citrinin was eluted with $1 \mathrm{~mL}$ of methanol:10 mM phosphoric acid (70:30, v:v) into a glass syringe barrel at a rate of slower than $1 \mathrm{drop} / \mathrm{second}$. For HPLC-FLD analysis, $40 \mu \mathrm{L}$ of the aliquot was injected.

\section{HPLC-FLD conditions}

The chromatographic analysis was conducted using an LC-20A Shimadzu (Kyoto, Japan) high-performance liquid chromatographic system coupled to an RF-10A XL fluorescence detector. The chromatographic separation was performed using a reversed-phase Phenomenex HPLC column $\left(C_{18}, 250 \mathrm{~mm} x\right.$ $4.6 \mathrm{~mm}, 5$ m, 100 A, Phenomenex, Torrance, CA, USA) with a mobile phase of acetonitrile:water:2-propanol (30:65:5, v/v/V, $\mathrm{pH} 2.95$ ) at a flow rate of $1 \mathrm{~mL} \mathrm{~min}^{-1}$. The column temperature was kept at $25^{\circ} \mathrm{C}$. The fluorescence detection condition was at $330 \mathrm{~nm}$ for excitation and $500 \mathrm{~nm}$ for emission in the citrinin analysis. The retention time was about 11.5-12.5 min.

\section{Method validation}

The linearity of the method was assessed using the calibration curve, established with nine levels of citrinin in the final concentrations of $0.25,0.5,1,2.5,5,10,25,50$ and $100 \mathrm{ng} / \mathrm{g}$ in the meat samples. The method selectivity was validated by analysing the extracts of citrinin-free blank and the same spiked samples at $5 \mathrm{ng} / \mathrm{g}$ citrinin. The recovery experiments were performed on citrinin-free meat samples by spiking with the citrinin standard solutions to obtain the final concentrations of 1-100 ng/g for LLE, 2.5-100 ng/g for QuEChERS, and 0.25-100 $\mathrm{ng} / \mathrm{g}$ for IAC. For the linearity and recovery studies, the four experiments were repeated, and each injected three times.

The method precision for the intra-day assay was assessed by analysing four independent spiked samples at five concentrations $(0.25-100 \mathrm{ng} / \mathrm{g})$ in three-replicated injections on the same day. The inter-day analysis was performed by analysing spiked samples at five concentrations $(0.25-100 \mathrm{ng} / \mathrm{g})$ in threereplicated injections on four consecutive days. The relative standard deviation of replicate results (RSDr) was used to evaluate intra- and inter-day precision. The method sensitivity was assessed by using the limit of detection (LOD; signal-to-noise ratio $=3$ ) and the limit of quantification ( $L O Q$; signal-to-noise ratio $=10)$ for citrinin. The method stability was determined with $5 \mathrm{ng} / \mathrm{g}$ citrinin-spiked samples at $25^{\circ} \mathrm{C}, 4^{\circ} \mathrm{C}$ and $-20^{\circ} \mathrm{C}$ on the analysis day of 1,3 and 10 .

\section{RESULTS AND DISCUSSION}

\section{Method performance}

No interfering peak was observed at the retention time of citrinin in the meat products after LLE, QuEChERS multi-residue and IAC methods. The calibration curve was linear at $0.25-$ $100 \mathrm{ng} / \mathrm{g}$ in the meat products with a correlation coefficient $r^{2}>0.9975$ (Table 1). The LOD levels were calculated to be $0.17-$ $0.33 \mathrm{ng} / \mathrm{g}$ for LLE, $0.33-1.67 \mathrm{ng} / \mathrm{g}$ for QuEChERS multi-residue and $0.083 \mathrm{ng} / \mathrm{g}$ for IAC; and the LOQ levels were $1 \mathrm{ng} / \mathrm{g}$ for LLE, $2.5 \mathrm{ng} / \mathrm{g}$ for QuEChERS multi-residue and $0.25 \mathrm{ng} / \mathrm{g}$ for IAC.

The mean recoveries from the meat products were 64.7187.58\% for LLE (at 1-100 ng/g), 62.74-78.54\% for QuEChERS multi-residue (at 2.5-100 ng/g), and 87.26-95.02\% for IAC (at 0.25-100 $\mathrm{ng} / \mathrm{g}$ ) with a relative standard deviation (RSDr) less than $7.13 \%$ (Table 2). The inter-day repeatability recoveries

Table 1. Linearity of citrinin in the meat products.

\begin{tabular}{|c|c|c|c|c|c|}
\hline & & Range (ng/g) & Calibration equation & $r^{2}$ & LOD (ng/g) \\
\hline \multirow{3}{*}{ LLE } & Salami & $1-100$ & $y=5.7094 x+0.2787$ & 0.9997 & 0.167 \\
\hline & Sausage & $1-100$ & $y=6.1928 x+1.0844$ & 0.9997 & 0.330 \\
\hline & Mince meat & $1-100$ & $y=6.445 x+2.4693$ & 0.9986 & 0.167 \\
\hline \multirow{3}{*}{$\begin{array}{l}\text { QuEChERS } \\
\text { multi-residue }\end{array}$} & Salami & $2.5-100$ & $y=5.3166 x+0.281$ & 0.9996 & 1.670 \\
\hline & Sausage & $2.5-100$ & $y=6.4089 x+5.3636$ & 0.9987 & 0.830 \\
\hline & Mince meat & $2.5-100$ & $y=5.0567 x+3.231$ & 0.9975 & 0.330 \\
\hline \multirow{3}{*}{ IAC } & Salami & $0.25-100$ & $y=7.1135 x+4.4583$ & 0.9995 & 0.083 \\
\hline & Sausage & $0.25-100$ & $y=6.9218 x+3.729$ & 0.9990 & 0.083 \\
\hline & Mince meat & $0.25-100$ & $y=7.206 x+1.928$ & 0.9990 & 0.083 \\
\hline
\end{tabular}


were mean $\geq 62.40 \%, \geq 61.60 \%$, and $\geq 86.60 \%$, and the intra-day repeatability recoveries were mean $\geq 66.50 \%$, $\geq 64.30 \%$, and $\geq 87.20 \%$ for LLE (at 1-100 ng/g), QuEChERS multi-residue (at 2.5-100 ng/g), and IAC (at 0.25-100 ng/g), respectively (Table 3). EC Regulation No 519/2014 stated that for all levels of citrinin recoveries are acceptable in the range of $70-120 \%$ and the RSDr should be <22\% (EU, 519/2014). According to our study, we observed good precision using the IAC method; hence, we performed the IAC method for analysing the meat samples.

For the method stability studies, $5 \mathrm{ng} / \mathrm{g}$ citrinin-spiked samples were analysed at $25^{\circ} \mathrm{C}, 4^{\circ} \mathrm{C}$ and $-20^{\circ} \mathrm{C}$. No change in recovery was observed after 1-3 days whereas the recovery decreased to $12 \pm 3.4 \%$ after 10 days.

Consistent with our results, Markov et al. (2013) showed that the citrinin recovery was $93.5 \%$ with a good precision of RSD 9.39\% in the meat products after IAC-extraction following HPLC-FLD determination. They also observed the LOD level as $0.5 \mathrm{ng} / \mathrm{g}$, the LOQ level as $1 \mathrm{ng} / \mathrm{g}$ (Markov et al., 2013). There are limited studies the reporting the presence of citrinin in meat products. Marley et al. (Marley, Brown, Leeman, \& Donnelly, 2016) showed that $L O Q$ for citrinin in red yeast rice was 10 $\mathrm{ng} / \mathrm{g}$, with an LOD of $3 \mathrm{ng} / \mathrm{g}$ and recoveries ranged from 80 to 110\% after IAC cleanup and HPLC-FLD. In a study from JiménezLópez et al. (Jiménez-López, Llorent-Martínez, Ortega-Barrales, \& Ruiz-Medina, 2014), developed a fluorometric flow-through optosensor using Sephadex SPC-25 as solid support for citrinin analysis in dietary supplements containing red yeast rice and obtained an LOD value of $10.5 \mathrm{ng} / \mathrm{mL}$ with RSDs lower than 3\%. Application of fluorescent immunochromatographic test strips to detect citrinin in Monascus fermented food demonstrated high recoveries (86.8-113.0\%) and low RSDs (1.8-15.3\%) (Chen, Xu, Ma, Cui, Sun, \& Zhang, 2019). In red fermented rice samples, the limit of detection was obtained as $1.0 \mathrm{ng} / \mathrm{g}$ for LC-MS/MS and $250 \mathrm{ng} / \mathrm{g}$ for HPLC-FLD (Ji et al., 2015).

Data obtained in the present study indicated that the IAC extraction method was the most effective method for citrinin extraction from the meat products and had good precision. Therefore, citrinin residue analysis in various meat products was conducted with IAC method, then analysed using HLPC-FLD.

\section{Citrinin in meat products}

The citrinin residue analysis was conducted for over a decade, and the surveys are still in progress worldwide. The physical conditions, such as climate change, affect the mycotoxin levels in food products and lead to concerns about food safety (Paterson \& Lima, 2010; Tirado, Clarke, Jaykus, McQuatters-Gollop, \& Frank, 2010); thus, annual monitoring all over the world is crucial to detect the residue levels and limit the possible health risks. Red yeast rice is widely used as a preservative and food colorant, especially, in meat products. American and European countries restrict the use of red yeast rice, but it has been still very common in Asian cuisine. Monacus purpureus fermented red yeast rice could be contaminated by citrinin, then, citrinin can be found in food products such as meat products which contain red yeast rice as a food colorant (EFSA, 2012).

Table 2. The recoveries from different meat products for LLE, QuEChERS multi-residue and IAC methods $(n=4)$.

\begin{tabular}{|c|c|c|c|c|c|c|c|c|c|}
\hline & \multicolumn{3}{|c|}{ LLE } & \multicolumn{3}{|c|}{ QuEChERS multi-residue } & \multicolumn{3}{|c|}{ IAC } \\
\hline & $\begin{array}{l}\text { Spiking } \\
\text { level } \\
\text { (ng/g) }\end{array}$ & $\begin{array}{l}\text { Mean } \\
\text { recovery } \\
(\%) \pm S D\end{array}$ & $\begin{array}{l}\text { RSDr } \\
(\%)\end{array}$ & $\begin{array}{l}\text { Spiking } \\
\text { level } \\
(n g / g)\end{array}$ & $\begin{array}{l}\text { Mean } \\
\text { recovery } \\
(\%) \pm S D\end{array}$ & $\begin{array}{c}\text { RSDr } \\
(\%)\end{array}$ & $\begin{array}{l}\text { Spiking } \\
\text { level } \\
(\mathrm{ng} / \mathrm{g})\end{array}$ & $\begin{array}{l}\text { Mean } \\
\text { recovery } \\
(\%) \pm S D\end{array}$ & RSDr (\%) \\
\hline 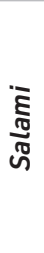 & $\begin{array}{c}1 \\
2.5 \\
5 \\
10 \\
25\end{array}$ & $\begin{array}{l}66.07 \pm 0.04 \\
72.65 \pm 0.07 \\
79.01 \pm 0.08 \\
86.34 \pm 0.39 \\
86.93 \pm 0.67\end{array}$ & $\begin{array}{l}5.63 \\
6.86 \\
1.96 \\
3.52 \\
1.84\end{array}$ & $\begin{array}{c}2.5 \\
5 \\
10 \\
25\end{array}$ & $\begin{array}{l}66.06 \pm 0.12 \\
68.17 \pm 0.15 \\
68.80 \pm 0.38 \\
76.47 \pm 0.75\end{array}$ & $\begin{array}{l}7.13 \\
4.94 \\
3.27 \\
3.91\end{array}$ & $\begin{array}{c}0.25 \\
0.5 \\
1 \\
2.5 \\
5 \\
10 \\
25\end{array}$ & $\begin{array}{l}91.98 \pm 0.01 \\
91.51 \pm 0.02 \\
94.45 \pm 0.03 \\
92.55 \pm 0.11 \\
92.62 \pm 0.06 \\
94.01 \pm 0.22 \\
95.02 \pm 0.35\end{array}$ & $\begin{array}{l}2.56 \\
3.25 \\
1.92 \\
4.17 \\
2.73 \\
1.78 \\
1.62\end{array}$ \\
\hline 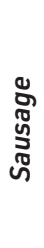 & $\begin{array}{c}1 \\
2.5 \\
5 \\
10 \\
25\end{array}$ & $\begin{array}{l}64.71 \pm 0.03 \\
69.50 \pm 0.06 \\
77.96 \pm 0.15 \\
75.91 \pm 0.40 \\
83.84 \pm 0.71\end{array}$ & $\begin{array}{l}4.27 \\
3.29 \\
3.78 \\
2.01 \\
4.57\end{array}$ & $\begin{array}{c}2.5 \\
5 \\
10 \\
25\end{array}$ & $\begin{array}{l}62.74 \pm 0.10 \\
66.01 \pm 0.16 \\
72.14 \pm 0.24 \\
78.54 \pm 1.14\end{array}$ & $\begin{array}{l}6.57 \\
4.78 \\
3.36 \\
3.97\end{array}$ & $\begin{array}{c}0.25 \\
0.5 \\
1 \\
2.5 \\
5 \\
10 \\
25\end{array}$ & $\begin{array}{l}89.06 \pm 0.02 \\
88.77 \pm 0.01 \\
85.62 \pm 0.06 \\
90.41 \pm 0.03 \\
88.96 \pm 0.17 \\
88.95 \pm 0.25 \\
89.68 \pm 0.66\end{array}$ & $\begin{array}{l}5.22 \\
2.24 \\
5.56 \\
2.18 \\
3.47 \\
1.66 \\
2.43\end{array}$ \\
\hline 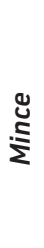 & $\begin{array}{c}1 \\
2.5 \\
5 \\
10 \\
25\end{array}$ & $\begin{array}{l}75.10 \pm 0.04 \\
76.41 \pm 0.11 \\
83.56 \pm 0.38 \\
85.04 \pm 0.35 \\
87.58 \pm 0.76\end{array}$ & $\begin{array}{l}5.21 \\
5.77 \\
4.24 \\
2.29 \\
3.49\end{array}$ & $\begin{array}{c}2.5 \\
5 \\
10 \\
25\end{array}$ & $\begin{array}{l}66.12 \pm 0.10 \\
65.28 \pm 0.22 \\
71.99 \pm 0.18 \\
72.77 \pm 0.89\end{array}$ & $\begin{array}{l}6.14 \\
6.48 \\
2.48 \\
5.40\end{array}$ & $\begin{array}{c}0.25 \\
0.5 \\
1 \\
2.5 \\
5 \\
10 \\
25\end{array}$ & $\begin{array}{l}90.41 \pm 0.01 \\
92.18 \pm 0.01 \\
90.66 \pm 0.03 \\
89.63 \pm 0.11 \\
87.26 \pm 0.07 \\
90.38 \pm 0.15 \\
91.46 \pm 0.46\end{array}$ & $\begin{array}{l}3.91 \\
2.73 \\
2.24 \\
2.86 \\
1.93 \\
1.73 \\
1.35\end{array}$ \\
\hline
\end{tabular}




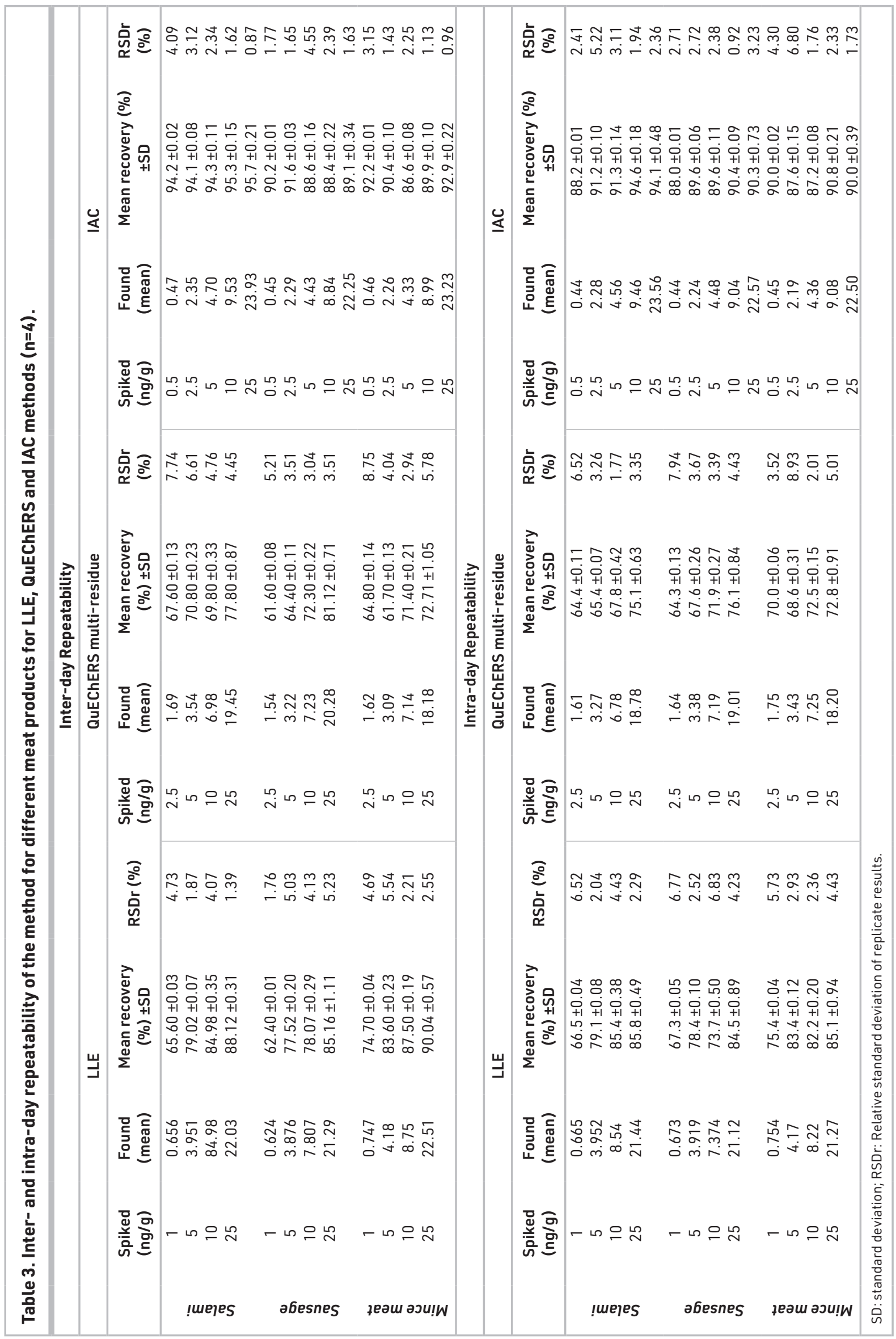


Table 4. Citrinin occurrence in total of $\mathbf{3 2}$ meat products as determined by IAC-HPLC-FLD.

\begin{tabular}{|lccccc|}
\hline & No. of samples & Positive (\%) & LOD-LOQ (\%) & Range $(\mathbf{n g} / \mathbf{g})$ & Mean \pm SD \\
\hline Salami & 7 & - & - & - & - \\
Sausage & 19 & $6(36.84)$ & $1(5.26)$ & $0.28-1.79$ & $0.867 \pm 0.54$ \\
Mince meat & 7 & - & - & - & - \\
Total & 33 & $7(21.87)$ & $1(3.12)$ & $0.083-1.79$ & $0.867 \pm 0.54$ \\
\hline
\end{tabular}

The analytical results in a total of 33 meat products (31 branded and 2 unlicensed), collected randomly from supermarkets, delicatessens and butchers in Istanbul, were shown in Table 4. Only, 6 out of the 19 (36.84\%) sausage samples contained citrinin at the concentration range of $0.28-1.79 \mathrm{ng} / \mathrm{g}$ and in one sample citrinin level was found at LOD level $(0.083 \mathrm{ng} / \mathrm{g})$, whereas citrinin was not detected in seven of salami and six of mince samples. Markov et al. (2013) analysed fermented meat products ( $n=90$ ) by IAC-HPLC-FLD and reported that $5.55 \%$ of the products were contaminated with citrinin at the level of LOQ $(1 \mathrm{ng} / \mathrm{g})$. There is a lack of data on citrinin levels in meat products. Therefore, when we considered the studies in red yeast rice products, Marley et al. (2016) showed that five of the nine samples containing citrinin levels exceeded the EU limit in food supplements based on rice fermented with the red yeast M. purpureus obtained from different parts of China. Accordingly, survey results from Taiwan showed that mean levels of citrinin contamination were 13.3, and $0.1 \mu \mathrm{g} / \mathrm{g}$ for red yeast rice (raw material), and red yeast rice processed products, respectively (Liao et al., 2014). $\mathrm{Ji}$ et al. (2015) observed that citrinin was found in the range of 0.14$44.24 \mathrm{\mu g} / \mathrm{g}$ in 10 of 12 commercial red fermented rice products.

In 2014, the citrinin concentration in red yeast rice was set at a limit of $2 \mathrm{ng} / \mathrm{g}$ by European Commission Regulation (EC) 212/2014 (EU, 212/2014). No limit was set for the other food products. Indeed, in Turkey, no limit was set even for red yeast rice regarding the citrinin residues in food products. According to our results, three of six citrinin positive meat samples contained citrinin levels of more than $1 \mathrm{ng} / \mathrm{g}$ which is $50 \%$ of the maximum limit for red yeast rice in the EU. Regarding the high consumption of fermented meat products containing red yeast rice which is the source of citrinin, the need for continuous monitoring of meat products, particularly, unbranded and produced in uncontrolled facilities is urged. Therefore, the citrinin levels of meat products as well as in other food products especially in red yeast rice products should be carefully considered. Furthermore, there is a need to set the limit of citrinin in various food products in the EU and Turkey.

Peer-review: Externally peer-reviewed.

Author Contributions: Conception/Design of Study- G.Ö., F.M.S., S.Ö.; Data Acquisition- G.Ö., F.M.S.; Data Analysis/Interpretation- G.Ö., F.M.S., S.Ö.; Drafting Manuscript- G.Ö., S.Ö., E.Ö.; Critical Revision of Manuscript- G.Ö., S.Ö., E.Ö.; Final Approval and Accountability- F.M.S., E.Ö., S.Ö., G.Ö.; Technical or Material Support- G.Ö.; Supervision- G.Ö., S.Ö.

Conflict of Interest: The authors have no conflict of interest to declare.

Financial Disclosure: This study was supported by the Research Fund of Istanbul University (Project No: 47083).

\section{REFERENCES}

- $\quad$ Chen, E., Xu, Y., Ma, B., Cui, H., Sun, C., \& Zhang, M. (2019). Carboxyl-Functionalized, Europium Nanoparticle-Based Fluorescent Immunochromatographic Assay for Sensitive Detection of Citrinin in Monascus Fermented Food. Toxins, 11(10), 605.

- Chia-Hao, C., Feng-Yili, Y., Li-Ting, W., Yi-Shen, L., \& Biing-Hui, L. (2009). Activation of ERK and JNK signaling pathways by mycotoxin citrinin in humans cells. Toxicology and Applied Pharmacology, 237, 281-287.

- Childress, L., Gay, A., Zargar, A., \& Ito, M. K. (2013). Review of red yeast rice content and current Food and Drug Administration oversight. Journal of Clinical Lipidology, 7(2), 117-122.

- Dick, R., Baumann, U., \& Zimmerli, B. (1988). Occurrence of citrinin in cereal grains. Mitteilungen aus dem Gebiete der Lebensmitteluntersuchung und Hygiene, 79, 159-164.

- $\quad$ Duarte, S. C., Pena, A., \& Lino, C. M. (2010). A review on ochratoxin A occurrence and effects of processing of cereal and cereal derived food products. Food Microbiology, 27(2), 187-198.

EFSA, Panel on Contaminants in the Food Chain (CONTAM). (2012). Scientific Opinion on the risks for public and animal health related to the presence of citrinin in food and feed. EFSA Journal, 10(3), 2605.

El Adlouni, C., Tozlovanu, M., Naman, F., Faid, M., \& Pfohl-Leszkowicz, A. (2006). Preliminary data on the presence of mycotoxins (ochratoxin A, citrinin and aflatoxin B1) in black table olives "Greek style" of Moroccan origin. Molecular Nutrition \& Food Research, 50(6), 507-512. El-Kady, I. A., El-Maraghy, S. S. M., \& Mostafa, M. E. (1995). Natural occurrence of mycotoxins in different spices in Egypt. Folia Microbiologica, 40(3), 297-300.

- $\quad$ European Union Commission Regulation (EU) No 212/2014 of 6 March 2014 amending Regulation (EC) No 1881/2006 as regards maximum levels of the contaminant citrinin in food supplements based on rice fermented with red yeast Monascus purpureus. https://publications.europa.eu/en/publication-detail/-/ publication/26b34f77-a5d1-11e3-8438-01aa75ed71a1 (Accessed: 26 Jul 2019).

- European Union Commission Regulation (EU) No 519/2014 of 16 May 2014 amending Regulation (EC) No 401/2006 as regards methods of sampling of large lots, spices and food supplements, performance criteria for T-2, HT-2 toxin and citrinin and screening methods of analysis. https://www.fsai.ie/uploadedFiles/ Reg519_2014.pdf (Accessed: 31 Jun 2019).

Franco, C. M., Fente, C. A., Vazquez, B., Cepeda, A., Lallaoui, L., Prognon, P., \& Mahuzier, G. (1996). Simple and sensitive high-performance liquid chromatography-fluorescence method for the determination of citrinin application to the analysis of fungal cultures and cheese extracts. Journal of Chromatography A, 723(1), 69-75. Gupta, R. C., Srivastava, A., \& Lall, R. (2018). Ochratoxins and citrinin. In Veterinary Toxicology (Third Edition) (pp. 1019-1027).

- Hackbart, H., Prietto, L., Primel, E. G., Garda-Buffon, J., \& BadialeFurlong, E. (2012). Simultaneous extraction and detection of ochratoxin A and citrinin in rice. Journal of the Brazilian Chemical Society, 23(1), 103-109. 
- Jackson, L. K., \& Ciegler, A. (1978). Production and analysis of citrinin in corn. Applied and Environmental Microbiology, 36(3), 408-411.

- Janardhana, G. R., Raveesha, K. A., \& Shetty, H. S. (1999). Mycotoxin contamination of maize grains grown in Karnataka (India). Food and Chemical Toxicology, 37(8), 863-868.

- Ji, X., Xu, J., Wang, X., Qi, P., Wei, W., Chen, X., ... \& Zhou, Y. (2015). Citrinin determination in red fermented rice products by optimized extraction method coupled to liquid chromatography tandem mass spectrometry (LC-MS/MS). Journal of Food Science, 80(6), T1438-T1444.

- Jiménez-López, J., Llorent-Martínez, E. J., Ortega-Barrales, P., \& Ruiz-Medina, A. (2014). Multi-commutated fluorometric optosensor for the determination of citrinin in rice and red yeast rice supplements. Food Additives \& Contaminants: Part A, 31(10), 1744-1750.

- Kononenko, G. P., \& Burkin, A. A. (2008). A survey on the occurrence of citrinin in feeds and their ingredients in Russia. Mycotoxin Research, 24(1), 3-6.

- $\quad$ Li, F. Q., Xu, G. R., Li, Y.W., Chen, Y., \& Ji, R. (2005). Natural occurrence of citrinin in Monascus products. Wei sheng yan jiu=Journal of Hygiene Research, 34(4), 451-454.

- $\quad$ Li, Y., Zhou, Y. C., Yang, M. H., \& Ou-Yang, Z. (2012). Natural occurrence of citrinin in widely consumed traditional Chinese food red yeast rice, medicinal plants and their related products. Food Chemistry, 132(2), 1040-1045.

- $\quad$ Liao, C. D., Chen, Y. C., Lin, H. Y., Chiueh, L. C., \& Shih, D. Y. C. (2014). Incidence of citrinin in red yeast rice and various commercial Monascus products in Taiwan from 2009 to 2012. Food Control, 38, 178-183.

- Ma, J., Li, Y., Ye, Q., Li, J., Hua, Y., Ju, D ... Chang, M. (2000). Constituents of red yeast rice, a traditional Chinese food and medicine. Journal of Agricultural and Food Chemistry, 48(11), 5220-5225.

- Markov, K., Pleadin, J., Bevardi, M., Vahčić, N., Sokolić-Mihalak, D., \& Frece, J. (2013). Natural occurrence of aflatoxin B1, ochratoxin A and citrinin in Croatian fermented meat products. Food Control, 34(2), 312-317.

- Marley, E., Brown, P., Leeman, D., \& Donnelly, C. (2016). Analysis of citrinin in cereals, red yeast rice dietary supplement, and animal feed by immunoaffinity column cleanup and LC with fluorescence detection. Journal of AOAC International, 99(4), 1025-1031.

- Molinié, A., Faucet, V., Castegnaro, M., \& Pfohl-Leszkowicz, A. (2005). Analysis of some breakfast cereals on the French market for their contents of ochratoxin A, citrinin and fumonisin B1: development of a method for simultaneous extraction of ochratoxin A and citrinin. Food Chemistry, 92(3), 391-400.

- Moss, M. O. (2002). Mycotoxin review-1. aspergillus and penicillium. Mycologist, 16(3), 116-119.

- Nguyen, M. T., Tozlovanu, M., Tran, T. L., \& Pfohl-Leszkowicz, A. (2007). Occurrence of aflatoxin B1, citrinin and ochratoxin A in rice in five provinces of the central region of Vietnam. Food Chemistry, 105(1), 42-47.

- Nishijima, M. (1984). Tokyo Metropolitan Research Laboratory of Public Health, Hyakunincho, Shinjuku-ku, Tokyo 160, Japan. In Toxigenic Fungi: Their Toxins and Health Hazard: Proceedings of the Mycotoxin Symposia Held in the Third International Mycological Congress, Tokyo, August 30-September 3, 1983 (Vol. 7, p. 172). Elsevier Science Limited.

- Ostry, V., Malir, F., \& Ruprich, J. (2013). Producers and important dietary sources of ochratoxin A and citrinin. Toxins, 5(9), 1574-1586.

- $\quad$ Pal, M., Gizaw, F., Abera, F., Shukla, P. K., \& Hazarika, R. A. (2015). Mycotoxins: A growing concern to human and animal health. Beverage Food World, 42(5), 42-50.
Paterson, R. R. M., \& Lima, N. (2010). How will climate change affect mycotoxins in food?. Food Research International, 43(7), 1902-1914.

Petkova-Bocharova, T., Castegnaro, M., Michelon, J., \& Maru, V. (1991). Ochratoxin A and other mycotoxins in cereals from an area of Balkan endemic nephropathy and urinary tract tumours in Bulgaria. IARC scientific publications, (115), 83.

Pohland, A. E. (1993). Mycotoxins in review. Food Additives and Contaminants, 10(1), 17-28.

Polisenska, I., Pfohl-Leszkowicz, A., Hadjeba, K., Dohnal, V., Jirsa, O., Denesova, O., ... \& Macharackova, P. (2010). Occurrence of ochratoxin A and citrinin in Czech cereals and comparison of two HPLC methods for ochratoxin A detection. Food Additives and Contaminants, 27(11), 1545-1557.

- Rawat, S. (2015). Food Spoilage: Microorganisms and their prevention. Asian Journal of Plant Science and Research, 5(4), 47-56.

Saxena, J., \& Mehrotra, B. S. (1989). Screening of spices commonly marketed in India for natural occurrence of mycrotoxins. Journal of Food Composition and Analysis, 2(3), 286-292.

Shu, P. Y., \& Lin, C. H. (2002). Simple and sensitive determination of citrinin in Monascus by GC-selected ion monitoring mass spectrometry. Analytical Sciences, 18(3), 283-287.

- $\quad$ Speijers, G. J. A., \& Speijers, M. H. M. (2004). Combined toxic effects of mycotoxins. Toxicology Letters, 153(1), 91-98.

Srianta, I., Ristiarini, S., Nugerahani, I., Sen, S. K., Zhang, B. B., Xu, G. R., \& Blanc, P. J. (2014). Recent research and development of Monascus fermentation products. International Food Research Journal, 21(1), 1-12.

- $\quad$ Talmaciu, E., Sandu, I., \& Banu, T. (2008). Researches regarding the fungal contamination and the presence of citrinin in feed. Fungi \& Mycotoxins, 2, 212-217.

- $\quad$ Tirado, M. C., Clarke, R., Jaykus, L. A., McQuatters-Gollop, A., \& Frank, J. M. (2010). Climate change and food safety: A review. Food Research International, 43(7), 1745-1765.

- Tokusoglu, Ö., \& Bozoglu, F. (2010). Citrinin risk in black and green table olives: Simultaneous determination with ochratoxin-a by optimized extraction and IAC-HPLC-FD. Italian Journal of Food Science, 22(3), 284.

- Tölgyesi, Á., Stroka, J., Tamosiunas, V., \& Zwickel, T. (2015). Simultaneous analysis of Alternaria toxins and citrinin in tomato: an optimised method using liquid chromatography-tandem mass spectrometry. Food Additives and Contaminants: Part A, 32(9), 1512-1522.

- Vrabcheva, T., Usleber, E., Dietrich, R., \& Märtlbauer, E. (2000). Cooccurrence of ochratoxin A and citrinin in cereals from Bulgarian villages with a history of Balkan endemic nephropathy. Journal of Agricultural and Food Chemistry, 48(6), 2483-2488.

- Warth, B., Parich, A., Atehnkeng, J., Bandyopadhyay, R., Schuhmacher, R., Sulyok, M., \& Krska, R. (2012). Quantitation of mycotoxins in food and feed from Burkina Faso and Mozambique using a modern LC-MS/MS multitoxin method. Journal of agricultural and food chemistry, 60(36), 9352-9363.

Woo, P. C., Lam, C. W., Tam, E. W., Lee, K. C., Yung, K. K., Leung, C. K., ... \& Yuen, K. Y. (2014). The biosynthetic pathway for a thousandyear-old natural food colorant and citrinin in Penicillium marneffei. Scientific Reports, 4, 6728.

Xu, B. J., Jia, X. Q., Gu, L. J., \& Sung, C. K. (2006). Review on the qualitative and quantitative analysis of the mycotoxin citrinin. Food Control, 17(4), 271-285.

- Zaied, C., Zouaoui, N., Bacha, H., \& Abid, S. (2012). Natural occurrence of citrinin in Tunisian wheat grains. Food Control, 28(1), 106-109. 